\title{
Fifth Annual International Conference of The Society for the Advancement of Socio-Economics (SASE) \\ New York City \\ March 26-28, 1993
}

\section{Call for Papers}

The Fifth Annual International Conference of the Society for the Advancement of Socio-Economics (SASE) will be held in New York City, March 26-28, 1993. The theme of the conference is Incentives and Values as Foundations of Social Order.

John Kenneth Galbraith (Harvard Univesity) and Robert Heilbroner (New School for Social Research) are among the featured speakers.

Specific topics will include Markets and Democracy in Eastern Europe and Latin America, War and Conversion, Health Care, Ethics, Decision Making, Endogenous Growth, The Environment, Risk Taking, Micro and Macro Socio-Economics, and Gender Issues in the Workplace.

SASE is a group of academic scholars, policy makers, and business people devoted to the development of new theoretical and methodological frameworks which explain economic and more general choice behavior. Premised upon the belief that economic behavior is not an isolated, abstract phenomenon, socio-economics draws upon the disciplines of psychology, sociology, political science, philosophy, and history in an attempt to recognize the complexity of human decision-making processes, and to locate economic behavior within a philosophical, historical, institutional, and ethical context.

Those interested in presenting a paper, organizing a session, or learning more about SASE should write to $714 \mathrm{H}$ Gelman Library, $2130 \mathrm{H}$ Street NW, Washington, DC 20052 (phone, 202-944-8167; FAX, 202-994-1639).

\section{Third European Congress of Psychology Tampere, Finland July 4-9, 1993}

\section{Call for Poster Abstracts}

The Third European Congress of Psychology, organized by the Federation of Psychology Associations in Finland under the auspices of the European Federation of Professional Psychologists' Associations, will be held in Tampere, Finland, July 4-9, 1993.

Themes to be discussed and debated in symposia, workshops, and poster sessions, will include ones in Cognitive Psychology, Psychology of Behavior and Brain, Psychology of Communication, Developmental Psychology, and Social Psychology. All individual papers will be allocated to poster sessions which will occupy an important role in the program.

The deadline for the submission of abstracts is November 30, 1992.

For further information, contact the congress manager, Aira Raudasoja, III European Congress of Psychology, P.O. Box 905, SF-00101 Helsinki, Finland (Phone, +358 0701 3839; FAX, + 3580701 3919). 